\title{
Radiation Dose Escalation in Accelerated Hyperfractionated Radiotherapy for Stage III Non-small-cell Lung Cancer
}

\author{
KENTARO WADA $^{1}$, NORIKO KISHI ${ }^{1}$, NAOYUKI KANAYAMA ${ }^{1}$, TAKERO HIRATA ${ }^{1}$, MASAHIRO MORIMOTO ${ }^{1}$, \\ KOJI KONISHI ${ }^{1}$, FUMIO IMAMURA ${ }^{2}$, TERUKI TESHIMA ${ }^{1}$ and KAZUHIKO OGAWA ${ }^{3}$ \\ Departments of ${ }^{1}$ Radiation Oncology, and ${ }^{2}$ Thoracic Oncology, \\ Osaka International Cancer Institute Hospital, Osaka, Japan; \\ ${ }^{3}$ Department of Radiation Oncology, Osaka University Graduate School of Medicine, Osaka, Japan
}

\begin{abstract}
Aim: To identify clinical benefits of dose escalation in accelerated hyperfractionated radiotherapy $(A H-R T)$ for stage III non-small-cell lung cancer (NSCLC) using propensity score-matched (PSM) analysis. Materials and Methods: Our study retrospectively examined 294 patients undergoing definitive radiotherapy [131 patients, conventional once-daily radiotherapy (OD-RT); and 163, AH-RT] who were followedup for a median of 40.4 months. The impact of overall survival $(O S)$, progression-free survival (PFS), and locoregional control (LRC) was investigated. Results: Pre-PSM, the median OS, PFS, and LRC durations were 23.1 vs. 39.9 ( $p=0.03$ ), 8.9 vs. $13.5(p<0.01)$, and $12.9 v s .50 .3(p<0.01)$ months in the OD$R T$ and AH-RT groups, respectively. After-PSM (two matched groups of 144 patients), AH-RT was associated with better LRC [adjusted hazard ratio $(a H R)=0.59,95 \%$ confidence interval $(C I)=0.33-0.99, \quad p=0.04]$ and marginally better PFS $(a H R=0.65,95 \% \quad C I=0.41-1.03 ; p=0.06)$, but not $O S$ $(a H R=0.75,95 \% C I=0.46-1.24 ; p=0.26)$. Conclusion: After PSM analysis, dose escalation using AH-RT improved LRC and PFS in patients with locally advanced NSCLC. AH-RT can be a promising option for patients with advanced NSCLC.
\end{abstract}

Non-small-cell lung cancer (NSCLC) is a major cause of death worldwide. The current standard of care for locally advanced NSCLC is definitive radiotherapy (RT), specifically concurrent chemoradiotherapy (CCRT) with a total of $60 \mathrm{~Gy}$

This study was presented in part as an oral presentation at the 30th Annual Meeting of the Japanese Society for Radiation Oncology, Osaka, Japan in November 2017.

Correspondence to: Kentaro Wada, Department of Radiation Oncology, Osaka International Cancer Institute Hospital, 3-1-69 Otemae, Chuo-ku, Osaka 541-8567, Japan. E-mail: k_wada@ radonc.med.osaka-u.ac.jp

Key Words: Radiation, non-small-cell lung cancer, chemoradiation, accelerated hyperfractionation, propensity score matching. in 30 fractions $(1,2)$. Despite advances in radiation technology, treatment outcomes remain poor (3-6). Treatment intensification using conventional dose escalation beyond 60 Gy with CCRT has been investigated in order to improve local control and survival (3-6). However, the Radiation Therapy Oncology Group (RTOG) study 0617 showed that dose escalation to $74 \mathrm{~Gy}$ with the once-daily radiotherapy (OD-RT) resulted in inferior local control and median survival, possibly due to the need for a prolonged radiation treatment time (7).

Uncertainty exists regarding appropriate dose fractionation to use for intermediate dose escalation (i.e. to total doses between $60 \mathrm{~Gy}$ and $74 \mathrm{~Gy}$ ) with CCRT, and further investigations are required. Accelerated hyperfractionated radiotherapy (AH-RT), one approach to increasing RT intensity with shortened treatment time, can potentially improve local control and overall survival (OS) (8-10). A twice-daily AH-RT regimen of $64 \mathrm{~Gy}$ in 40 fractions with concurrent chemotherapy resulted in an excellent complete and partial response rate and median OS in a phase II study (11). Based on the previous study, we have treated selected patients with NSCLC using the AH-RT regimen. The objective of this study was to compare the locoregional control (LRC) and survival characteristics related to intermediate dose escalation in AH-RT using a propensity score-matched (PSM) pair analysis approach.

\section{Materials and Methods}

Patient population. After obtaining Institutional Review Board approval (no. 1606309044), retrospectively, consecutive patients with stage III NSCLC treated with definitive RT were reviewed. Before treatment, all patients gave written informed consent to use of their clinical information. Overall, 302 patients underwent treatment between November 2004 and June 2017, six with no histological evidence of malignancy and two diagnosed as having primary unknown lung cancer with mediastinum lymphadenopathy were excluded; 294 patients were included in the final cohort. In this non-randomized single-center study, decision of AH-RT regimen use was at the radiation oncologists' discretion. 
Baseline characteristics recorded included age, sex, Eastern Cooperative Oncology Group performance status (ECOGPS), treatment period, tumor size, clinical $\mathrm{N}$ classification, histology, epidermal growth factor receptor $(E G F R)$ mutation status, chemotherapy regimen, CCRT, total number of chemotherapy cycles, RT dose, RT treatment time, RT technique, and delay in RT. The clinical stage and $\mathrm{N}$ classification were defined according to the TNM system of the Union for International Cancer Control (UICC), 6th (until March 2009) and 7th (after April 2009) editions (12,13). Tumor size was measured on axial slice of pretreatment computed tomography $(\mathrm{CT})$. Some differences occurred in definition between clinical stages IIIA, IIIB, and clinical T classification; therefore, these were excluded. Clinical $\mathrm{N}$ classification showed no differences between editions. RT treatment time was calculated using calendar days. Causes of death were confirmed from clinical records, whereas those lost to follow-up were tracked through telephone survey.

RT technique. Most patients were treated with 3-dimensional conformal RT. The planning technique was based on the International Commission on Radiation Units and Measurements, Publication 62 Reports (14). Gross tumor volume (GTV) was defined as primary tumor and metastatic nodes. Clinical target volume (CTV) consisted of elective (CTV1) and high-risk CTV (CTV2). CTV2 was calculated by adding a 5-mm margin to GTV, while CTV1 included CTV2 and elective nodal areas of the mediastinum. Each CTV was expanded by $5 \mathrm{~mm}$ to define the planning target volumes (PTV1 and PTV2). In the OD-RT regimen, the prescription dose was $60 \mathrm{~Gy}$, conducted as $40 \mathrm{~Gy} / 20$ fractions for PTV1, and sequentially as $20 \mathrm{~Gy} / 10$ fractions for PTV2. For the AH-RT regimen, the prescribed doses were 64 Gy using 40 fractions administered twice daily over 4 weeks with concomitant boost technique (phase 1, $40 \mathrm{~Gy} / 20$ fractions for PTV1; phase 2, $24 \mathrm{~Gy} / 20$ fractions as the second daily fraction after a $6 \mathrm{~h}$ gap for PTV2). For both regimens, typical field arrangements consisted of four beams, usually anterior-posterior opposed fields for PTV1, and oblique opposed fields for PTV2.

Chemotherapy. Cisplatin $\left(80 \mathrm{mg} / \mathrm{m}^{2}\right)$ on day 1 combined with vinorelbine $\left(25 \mathrm{mg} / \mathrm{m}^{2}\right)$ on days 1 and 8 in 3-to 4-week intervals were delivered as concurrent and consolidation chemotherapy in 171 $(58.2 \%)$ patients. Another chemotherapy regimen was administered largely for those with comorbidities and older age. The main second choice of chemotherapy regimen was carboplatin plus paclitaxel, which was administered to 57 patients (19\%). Overall, four cycles of chemotherapy were administered, as far as possible. Total chemotherapy cycles, defined by the number of full-dose chemotherapy cycles used in CCRT and consolidation chemotherapy, excluded the number of weekly cycles of chemotherapy regimen and chemotherapy administered after recurrence.

Endpoints. The endpoints of this study were OS (time to death due to any cause), progression-free survival (PFS), and LRC; measured from the first day of treatment (including RT and chemotherapy). PFS was defined as at least $20 \%$ increase in the sum of target lesions diameters on CT, appearance of new lesions, or deaths resulting from primary NSCLC only; treatment-related deaths (counted as events and deaths from other causes) were censored. LRC was defined as absence of radiological progression of new lesions within the radiation field, and deaths from any cause without locoregional recurrence were censored.
Statistical analysis and PSM. In order to reduce selection bias, PSM methods were used. The propensity score (15) was estimated using a non-parsimonious multivariate logistic regression model with the use of AH-RT (dependent variable), and 10 baseline metrics (covariates). PSM used 1:1 matching protocol without replacement (nearest available method), with caliper width equal to 0.05 of logit of the propensity score standard deviation. Standard differences, estimated for all baseline covariates before and after matching to assess imbalance, if $<10.0 \%$ for a given covariate, indicated a relatively small imbalance (15). The area under the curve showed the model performance to be 0.79 [95\% confidence interval $(\mathrm{CI})=0.74-0.84$ ].

Sensitivity analyses were used to confirm the results of PSM analysis. Three other matched pairs (1:1 patient ratio), with sex, treatment period, and histology eliminated from the original 10 adjustment factors (no significant differences between OD-RT and AHRT groups in the original cohort in these three factors) were generated. Univariate and multivariate analyses of datasets before matching were performed. Factors with $p<0.02$ in the univariate analysis were included in the multivariate analysis. Additionally, weighted Cox regression with inverse probability of treatment weighting (IPTW) and Cox proportional hazards model in pre-PSM cohort, adjusted with propensity score as a single covariate, were also conducted. IPTW approach compares outcomes in two pseudo-populations with and without exposure, with similar covariate distributions (15). Outcomes were estimated using Kaplan-Meier method and log-rank test. Cox proportional hazards model was used to determine hazard ratios, adjusted for matched design in PSM cohorts. Reported $p$-values are two-sided, while $p<0.010$ and $p<0.05$ were considered significant and marginally significant, respectively. All statistical analyses were performed using JMP Pro version 10 (SAS Institute Inc., Cary, NC, USA), EZR (Saitama Medical Center, Jichi Medical University, Saitama, Japan), and a graphical user interface for R 2.13.0 (R Foundation for Statistical Computing, Vienna, Austria).

\section{Results}

Patient characteristics before and after PSM are presented in Table I. Of 294 patients, $131(44.6 \%)$ received treatment using OD-RT and 163 (55.4\%), using AH-RT. In the prematching cohort, patients treated with OD-RT were more likely to be $>70$ years, with poor ECOG PS, larger tumor size, and higher $\mathrm{N}$-classification. They tended to receive sequential CRT, and their total number of full-dose chemotherapy cycles were less than for AH-RT group. After PSM, baseline characteristics became generally comparable between groups (Table I), and all standard differences were confirmed to be $<10.0 \%$; indicating only small differences.

Median follow-up time was 40.4 (range $=0.37-170.3$ ) months. Before PSM, median OS, PFS and LRC for the OD-RT and AHRT groups were 23.1 vs. 39.9 ( $p=0.03) ; 8.9$ vs. $13.5(p<0.01)$; and $12.9 v s .50 .3(p<0.01)$ months, respectively (Figure 1). After PSM, the difference in LRC remained, with an adjusted hazard ratio (aHR) of 0.59 (95\% CI=0.33-0.99; $p=0.04)$. The difference in PFS remained marginally significant $(p=0.06)$, while the difference in OS was lost after PSM $(p=0.26)$ (Figure 2). Sensitivity analyses using PSM also demonstrated that LRC was significantly better for the AH-RT group when excluding sex 
Table I. Patient characteristics before and after propensity score matching (PSM).

\begin{tabular}{|c|c|c|c|c|c|c|c|}
\hline & & \multicolumn{3}{|c|}{ Before PSM } & \multicolumn{3}{|c|}{ After PSM } \\
\hline & & OD-RT $(n=131)$ & AH-RT $(n=163)$ & $p$-Value & OD-RT $(n=72)$ & AH-RT $(n=72)$ & $p$-Value \\
\hline \multirow[t]{3}{*}{ Age, years } & Median (IQR) & $66(61-72)$ & $63(56-68)$ & $<0.01$ & $63(58-68)$ & $63(56-70)$ & 0.53 \\
\hline & $<70, \mathrm{n}(\%)$ & $82(62.6)$ & $132(81)$ & $<0.01$ & $55(76.4)$ & $52(72.2)$ & 0.57 \\
\hline & $\geq 70, \mathrm{n}(\%)$ & $49(37.4)$ & $31(19)$ & & $17(23.6)$ & $20(27.8)$ & \\
\hline \multirow[t]{2}{*}{ Gender } & Male & $109(83.3)$ & 133 (81.6) & 0.71 & $61(84.7)$ & 63 (87.5) & 0.63 \\
\hline & Female & $22(16.8)$ & $30(18.4)$ & & $11(15.3)$ & $9(12.5)$ & \\
\hline \multirow[t]{2}{*}{ ECOG PS } & 0 & $62(47.3)$ & 109 (66.9) & $<0.01$ & $36(50)$ & $38(52.8)$ & 0.74 \\
\hline & $<1$ & $69(52.7)$ & $54(33.1)$ & & $36(50)$ & $34(47.2)$ & \\
\hline \multirow[t]{3}{*}{ Treatment period } & Up to $03 / 2009$ & $61(46.6)$ & $72(44.2)$ & 0.68 & $33(45.8)$ & $31(43.1)$ & 0.74 \\
\hline & From 04/2009 & $70(53.4)$ & $91(55.8)$ & & $39(54.2)$ & $41(56.9)$ & \\
\hline & Median (SD) & $48.3(22)$ & $40.9(19.3)$ & $<0.01$ & $46.0(23.5)$ & $42.8(21.9)$ & 0.42 \\
\hline \multirow[t]{3}{*}{ Tumor size } & $<50 \mathrm{~mm}$ & $69(52.7)$ & $114(70.0)$ & $<0.01$ & $44(61.1)$ & $44(61.1)$ & 1.0 \\
\hline & $\geq 50 \mathrm{~mm}$ & $62(47.3)$ & $49(30.0)$ & & $28(38.9)$ & $28(38.9)$ & \\
\hline & $0 / 1 / 2 / 3$ & $7 / 9 / 58 / 57$ & $6 / 15 / 94 / 48$ & 0.06 & $5 / 5 / 34 / 28$ & $4 / 6 / 33 / 29$ & 0.97 \\
\hline \multirow[t]{2}{*}{ N-Classification } & $0-2$ & $74(56.5)$ & 115 (70.6) & $<0.01$ & $44(61.1)$ & $43(59.7)$ & 0.87 \\
\hline & 3 & $57(43.5)$ & $48(29.4)$ & & $28(38.9)$ & $29(40.3)$ & \\
\hline \multirow[t]{3}{*}{ Histology } & SCC & $55(42)$ & $62(38)$ & 0.8 & $31(43.1)$ & $32(44.4)$ & 0.97 \\
\hline & $\mathrm{AC}$ & $67(51.2)$ & $89(54.6)$ & & $36(50)$ & $35(48.6)$ & \\
\hline & NSCLC-NOS & $9(0.07)$ & $12(0.07)$ & & $5(6.9)$ & $5(6.9)$ & \\
\hline \multirow[t]{3}{*}{$E G F R$ mutation } & Yes & $6(4.6)$ & $11(6.8)$ & 0.17 & $4(5.6)$ & $4(5.6)$ & 0.29 \\
\hline & No & $48(36.6)$ & $74(45.4)$ & & $25(34.7)$ & $34(47.2)$ & \\
\hline & Not assessed & $77(58.8)$ & $78(47.9)$ & & $43(59.7)$ & $34(47.2)$ & \\
\hline \multirow[t]{2}{*}{ Chemotherapy regimen } & $\mathrm{CV}$ & $52(39.7)$ & $119(73)$ & $<0.01$ & $42(58.3)$ & $40(55.6)$ & 0.88 \\
\hline & Other & $79(60.3)$ & $44(27)$ & & $30(41.7)$ & $32(44.4)$ & \\
\hline \multirow[t]{3}{*}{ Chemoradiotherapy } & Concurrent CRT & $86(65.6)$ & $152(93.3)$ & $<0.01$ & $42(58.3)$ & $40(55.6)$ & 0.74 \\
\hline & Sequential CRT & $31(23.7)$ & $8(4.9)$ & & $28(38.9)$ & $29(40.3)$ & \\
\hline & $\mathrm{RT}$ alone & $14(10.7)$ & $3(1.8)$ & & $2(2.8)$ & $3(4.2)$ & \\
\hline \multirow[t]{3}{*}{ Total no. of chemotherapy cycle } & 0 & $13(9.9)$ & $3(1.8)$ & $<0.01$ & $2(3.5)$ & $3(4.1)$ & 0.89 \\
\hline & $1-2$ & $55(42)$ & $52(31.9)$ & & 30 (41.7) & $31(43.1)$ & \\
\hline & $\geq 3$ & $63(48.1)$ & $108(66.3)$ & & $40(55.6)$ & $38(52.8)$ & \\
\hline Radiation dose (Gy) & Median (range) & $60(58-66)$ & $64(61-64)$ & $<0.01$ & $60(58-64)$ & $64(61-64)$ & $<0.01$ \\
\hline Radiation treatment time (days) & Median (IQR) & $44(43-48)$ & $30(29-33)$ & $<0.01$ & $44(43-48)$ & $29(28-34)$ & $<0.01$ \\
\hline \multirow[t]{2}{*}{ Treatment technique } & 3D-CRT & $122(93.1)$ & $163(100)$ & $<0.01$ & $72(100)$ & $72(100)$ & 1 \\
\hline & IMRT & $9(6.9)$ & $0(0)$ & & $0(0)$ & $0(0)$ & \\
\hline \multirow[t]{2}{*}{ RT delay $\geq 7$ days } & Yes & $32(24.4)$ & $34(20.9)$ & 0.47 & $18(25)$ & $17(23.6)$ & 0.85 \\
\hline & No & $99(75.6)$ & $129(79.1)$ & & $54(75)$ & $55(76.4)$ & \\
\hline \multirow[t]{3}{*}{ Cause of death } & Primary NSCLC & $76(89.4)$ & $94(84.7)$ & & $47(88.7)$ & $48(82.8)$ & \\
\hline & $\mathrm{AE}$ of the treatment & $7(8.2)$ & $2(1.8)$ & & $5(9.4)$ & $2(3.4)$ & \\
\hline & Other & $2(2.4)$ & $15(13.5)$ & & $1(1.9)$ & $8(13.8)$ & \\
\hline
\end{tabular}

OD-RT: Once daily radiotherapy; AH-RT: accelerated hyperfractionated radiotherapy; ECOG PS: Eastern Cooperative Oncology Group performance status; SCC: squamous cell carcinoma; AC: adenocarcinoma; NSCLC-NOS: non-small-cell lung cancer not otherwise specified; EGFR: epidermal growth factor receptor; CV: cisplatin + vinorelbine; 3D-CRT: 3-dimensional conformal radiotherapy; IMRT: intensity-modulated radiation therapy; AE: adverse event; IQR: interquartile range; SD: standard deviation.

( $p=0.03)$, treatment period $(p=0.01)$, and histology $(p=0.02)$. These three analyses showed marginal difference in PFS and none in OS. Multivariate analyses, which included variables with $p<0.2$ at univariate analysis suggested sex (male $v s$. female: $\mathrm{HR}=1.54,95 \% \mathrm{CI}=1.04-2.34 ; p=0.03)$, total chemotherapy cycles $(0-2 v s . \geq 3$ cycles: $\mathrm{HR}=1.34,95 \% \mathrm{CI}=1.02-1.09 ; p=0.04)$, and RT delay $(0-6 v s .>7$ days: $\mathrm{HR}=0.71,95 \% \mathrm{CI}=0.51-0.99$; $p=0.04$ ) as significant prognostic variables of OS and treatment period (up to 03/2009 vs. from 04/2009: $\mathrm{HR}=1.49,95 \% \mathrm{CI}=1.1$ -
$2.0 ; p<0.01) ; \mathrm{N}$ classification $(0-2$ vs. $3: \mathrm{HR}=0.67,95 \%$ $\mathrm{CI}=0.51-0.89 ; p<0.01)$ and total chemotherapy cycles $(0-2 v s$. $\geq 3$ cycles: $\mathrm{HR}=1.78,95 \% \mathrm{CI}=1.33-2.34 ; p<0.001)$ of $\mathrm{PFS}$; and treatment period (up to 03/2009 vs. from 04/2009: $\mathrm{HR}=1.55$, 95\% $\mathrm{CI}=1.09-2.2 ; p=0.01)$ and $\mathrm{RT}$ regimen (AH-RT $v s$. OD-RT, $\mathrm{HR}=0.63,95 \% \mathrm{CI}=0.44-0.89 ; p=0.01$ ) of LRC (Tables II and III). The results of these sensitivity analyses consistently showed better LRC and PFS for the AH-RT group and no difference in OS (Table IV). 

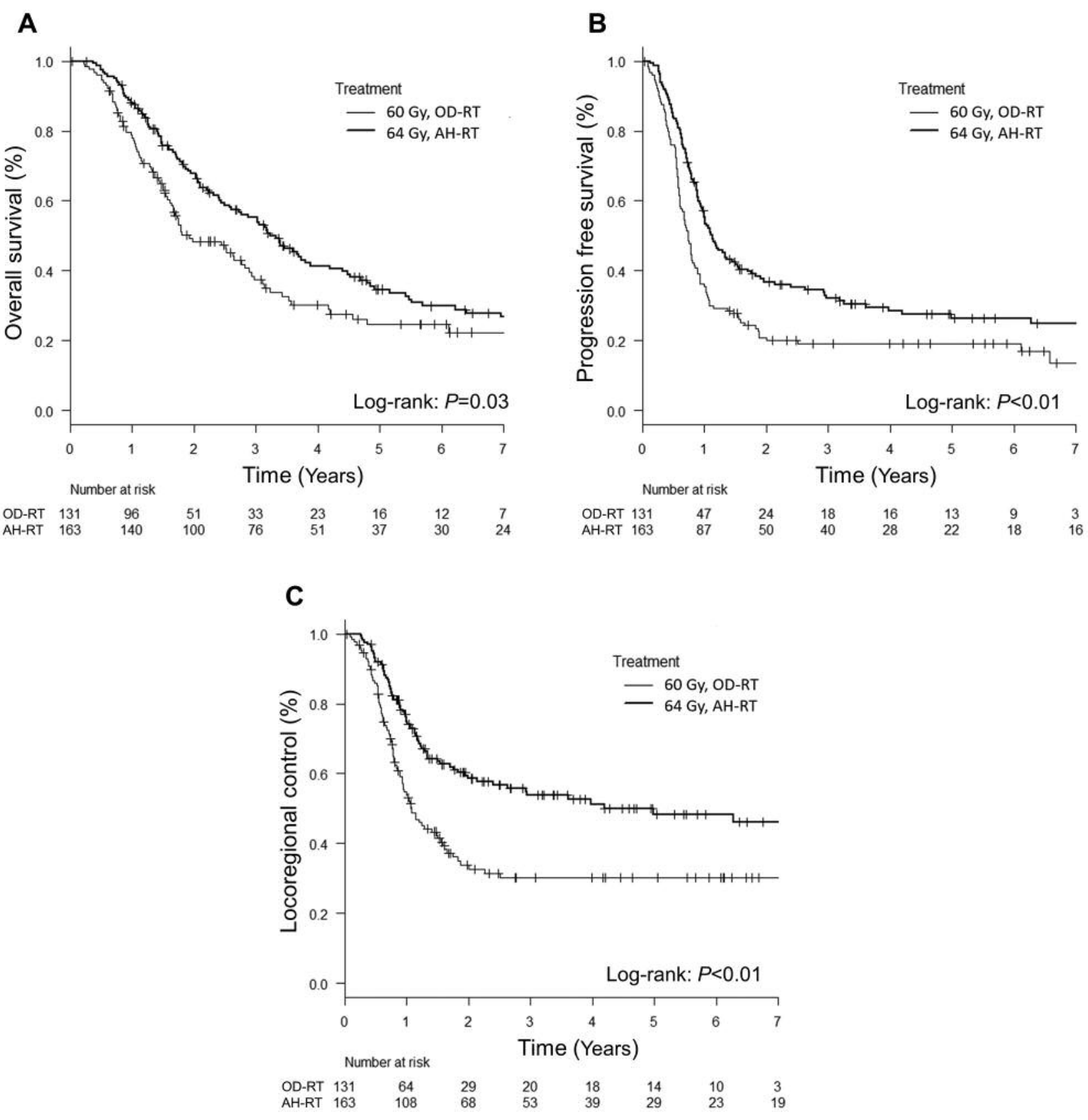

Figure 1. Kaplan-Meier-estimates. A: Overall survival, B: progression-free survival, and C: locoregional control before propensity score matching in patients with stage III non-small-cell lung cancer according to therapy. OD-RT: Once-daily radiotherapy; AH-RT: accelerated hyperfractionated radiotherapy.

During follow-up, 196 (66.7\%) patients died. In the ODRT group, more patients died from treatment-related adverse events (AEs). Nine patients died of other diseases in the ODRT group, of which, seven, one, and one died from AEs, secondary cancer, and cardiac event, respectively. In the AHRT group, two, nine, and two patients died from AE, secondary cancer, and cerebrovascular events; and one patient from each group died of Parkinson's disease, cardiac event, Nocardia pneumonia, and unknown causes, respectively. The nine deaths from AEs consisted of both radiation and infection-related pneumonia, except for one patient who died of multiple organ failure. 
A

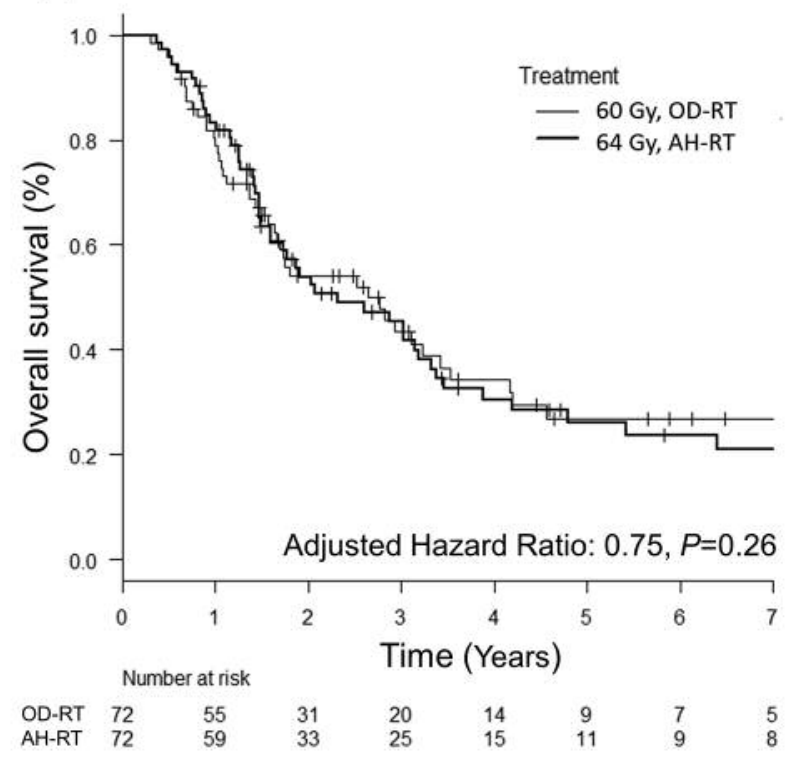

B

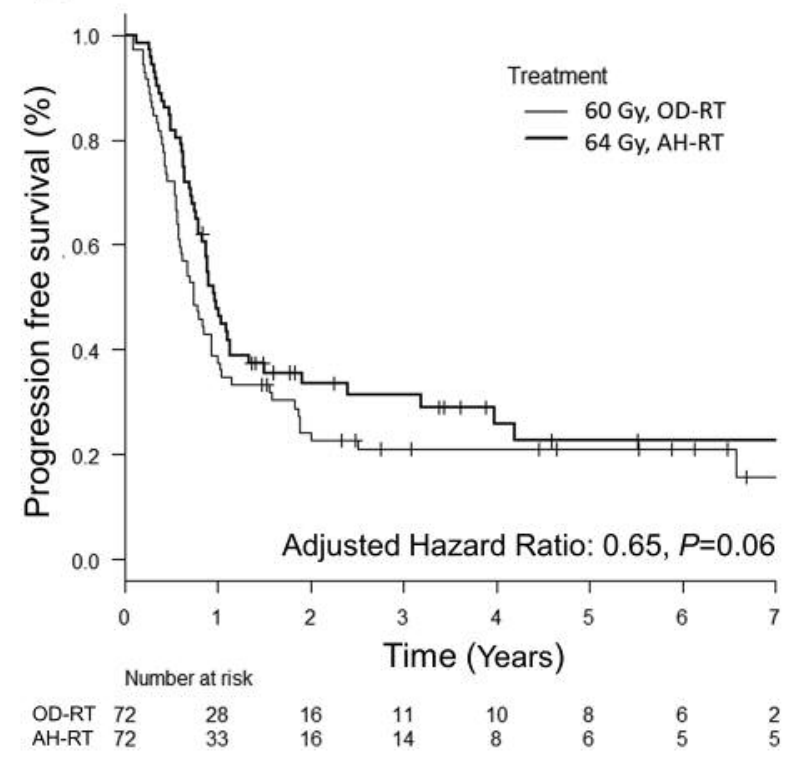

C
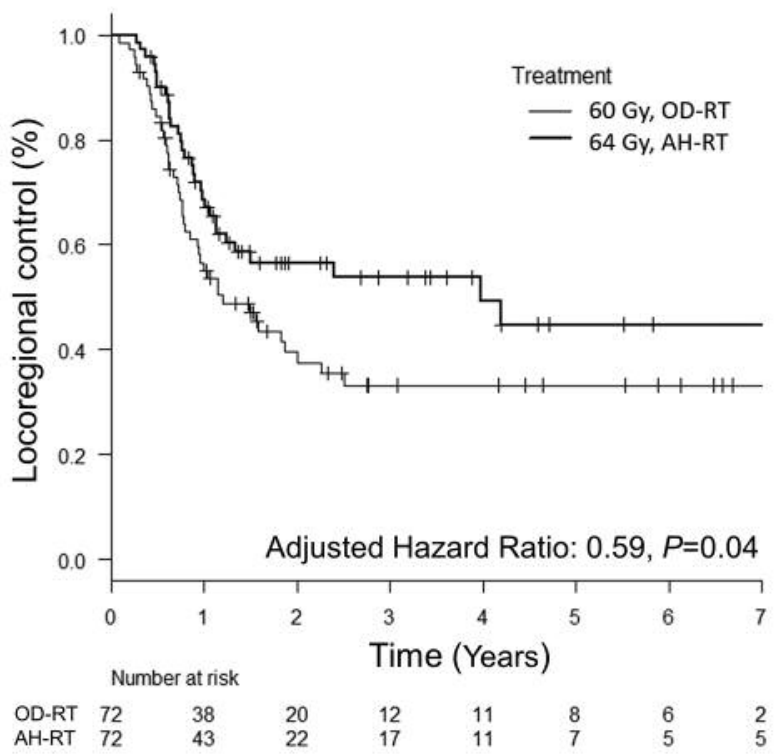

Figure 2. Kaplan-Meier-estimates. A: Overall survival, B: progression-free survival, and C: locoregional control after propensity score matching in patients with stage III non-small-cell lung cancer according to therapy. OD-RT: Once-daily radiotherapy; AH-RT: accelerated hyperfractionated radiotherapy.

\section{Discussion}

Propensity matched-pair analysis presented in this study showed association of dose escalation using AH-RT with LRC and PFS, but not OS. This finding was robustly confirmed by several sensitivity analyses. Treatment using AH-RT provided a means of RT intensification, which has the potential to improve OS (9). Series of continuous AH-RT trials have shown significant benefit of this modality in improving local control and OS, and confirmed the importance of RT treatment time as a factor in CRT for NSCLC $(9,16)$. Prolonging RT treatment time can negatively affect LRC and OS in patients with lung cancer (17). The radiobiological underpinning for this might be the accelerated repopulation of surviving tumor 
Table II. Impact of variables on overall survival (OS), progression-free survival (PFS), locoregional control (LRC) for 294 patients at univariate analyses.

\begin{tabular}{|c|c|c|c|c|c|c|c|c|c|c|}
\hline \multirow[b]{2}{*}{ Factor } & \multirow[b]{2}{*}{ Comparison } & \multicolumn{3}{|c|}{ OS } & \multicolumn{3}{|c|}{ PFS } & \multicolumn{3}{|c|}{ LRC } \\
\hline & & $\mathrm{HR}$ & $95 \% \mathrm{CI}$ & $p$-Value & $\mathrm{HR}$ & $95 \% \mathrm{CI}$ & $p$-Value & HR & $95 \% \mathrm{CI}$ & $p$-Value \\
\hline Age & $\geq 70 v s .<70$ Years & 1.65 & $1.2-2.24$ & $<0.01$ & 1.2 & $0.88-1.61$ & 0.23 & 1.3 & $0.9-1.84$ & 0.15 \\
\hline Gender & Male $v s$. female & 1.57 & $1.07-2.41$ & 0.03 & 1.12 & $0.79-1.63$ & 0.53 & 1.26 & $0.83-2.0$ & 0.3 \\
\hline Treatment period & $\begin{array}{l}\text { Up to } 03 / 2009 v s \text {. } \\
\text { from } 04 / 2009\end{array}$ & 1.14 & $0.85-1.52$ & 0.35 & 1.3 & $0.99-1.69$ & 0.06 & 1.53 & $1.11-2.11$ & $<0.01$ \\
\hline ECOG PS & $\geq 1$ vs. 0 & 1.29 & $0.97-1.71$ & 0.09 & 1.29 & $0.98-1.68$ & 0.06 & 1.23 & $0.89-1.7$ & 0.2 \\
\hline Histology & AC vs. other & 0.87 & $0.66-1.16$ & 0.37 & 1.05 & $0.81-1.37$ & 0.72 & 0.83 & $0.61-1.15$ & 0.27 \\
\hline Tumor size & $<50 v s . \geq 50 \mathrm{~mm}$ & 0.85 & $0.64-1.14$ & 0.24 & 0.93 & $0.71-1.23$ & 0.61 & 0.79 & $0.57-1.09$ & 0.15 \\
\hline $\mathrm{N}$-Classification & $0-2 v s . \geq 3$ & 0.89 & $0.67-1.2$ & 0.46 & 0.65 & $0.5-0.86$ & $<0.01$ & 0.78 & $0.57-1.09$ & 0.14 \\
\hline Chemotherapy regimen & CV vs. other & 0.66 & $0.5-0.89$ & $<0.01$ & 0.85 & $0.65-1.11$ & 0.22 & 0.82 & $0.59-1.13$ & 0.22 \\
\hline CRT & Concurrent $v s$. other & 0.62 & $0.45-0.89$ & $<0.01$ & 0.72 & $0.53-1.02$ & 0.05 & 0.54 & $0.37-0.79$ & $<0.01$ \\
\hline Total no. of chemotherapy cycles & $0-2 v s . \geq 3$ & 1.66 & $1.24-2.21$ & $<0.01$ & 1.64 & $1.25-2.14$ & $<0.01$ & 1.31 & $0.95-1.81$ & 0.1 \\
\hline RT regimen & $\mathrm{AH} v s . \mathrm{OD}$ & 0.73 & $0.55-0.97$ & 0.02 & 0.63 & $0.48-0.83$ & $<0.01$ & 0.52 & $0.38-0.71$ & $<0.01$ \\
\hline RT delay & $<7$ vs. $\geq 7$ Days & 0.66 & $0.49-0.92$ & 0.01 & 0.73 & $0.55-1.00$ & 0.04 & 0.75 & $0.52-1.09$ & 0.12 \\
\hline
\end{tabular}

ECOG PS: Eastern Cooperative Oncology Group performance status; AC: adenocarcinoma; CV: cisplatin + vinorelbine; CRT: concurrent chemoradiotherapy; RT: radiotherapy; OD: once-daily; AH: accelerated hyperfractionation.

Table III. Impact of variables on overall survival (OS), progression-free survival (PFS), locoregional control (LRC) for 294 patients at multivariate analyses including factors with $p<0.02$ in the univariate analysis.

\begin{tabular}{|c|c|c|c|c|c|c|c|c|c|c|}
\hline \multirow[b]{2}{*}{ Factor } & \multirow[b]{2}{*}{ Comparison } & \multicolumn{3}{|c|}{ OS } & \multicolumn{3}{|c|}{ PFS } & \multicolumn{3}{|c|}{ LRC } \\
\hline & & HR & $95 \% \mathrm{CI}$ & $p$-Value & HR & $95 \% \mathrm{CI}$ & $p$-Value & HR & $95 \% \mathrm{CI}$ & $p$-Value \\
\hline Age & $\geq 70 v s .<70$ Years & 1.28 & $0.89-1.81$ & 0.17 & - & - & - & 1.06 & $0.72-1.56$ & 0.75 \\
\hline Sex & Male vs. female & 1.54 & $1.04-2.39$ & 0.03 & - & - & - & - & - & - \\
\hline Treatment period & $\begin{array}{l}\text { Up to } 03 / 2009 v s \text {. } \\
\text { from } 04 / 2009\end{array}$ & - & - & - & 1.49 & $1.1-2.0$ & $<0.01$ & 1.54 & $1.09-2.2$ & 0.01 \\
\hline ECOG PS & $\geq 1$ vs. 0 & 1.26 & 0.94-1.69 & 0.11 & 1.27 & $0.96-1.67$ & 0.09 & - & - & - \\
\hline Histology & AC vs. other & - & - & - & - & - & - & - & - & - \\
\hline Tumor size & $<50 \mathrm{vs} . \geq 50 \mathrm{~mm}$ & - & - & - & - & - & - & 0.84 & $0.61-1.67$ & 0.29 \\
\hline $\mathrm{N}-$ Classification & $0-2 v s . \geq 3$ & - & - & - & 0.67 & $0.51-0.89$ & $<0.01$ & 0.86 & $0.62-1.2$ & 0.35 \\
\hline Chemotherapy regimen & CV vs. other & 0.91 & $0.64-1.29$ & 0.58 & - & - & - & - & - & - \\
\hline CRT & Concurrent $v s$. other & 0.73 & $0.49-1.14$ & 0.16 & 1.0 & $0.67-1.49$ & 0.95 & 0.78 & $0.5-1.23$ & 0.28 \\
\hline Total no. of chemotherapy cycles & $0-2 v s . \geq 3$ & 1.39 & $1.02-1.9$ & 0.04 & 1.78 & $1.33-2.38$ & $<0.01$ & 1.28 & $0.9-1.82$ & 0.17 \\
\hline RT regimen & $\mathrm{AH} v s . \mathrm{OD}$ & 0.98 & $0.71-1.38$ & 0.92 & 0.75 & $0.56-1.01$ & 0.06 & 0.63 & $0.44-0.9$ & 0.01 \\
\hline RT delay & $<7$ vs. $\geq 7$ Days & 0.71 & $0.51-0.99$ & 0.04 & 0.84 & $0.62-1.16$ & 0.29 & 0.81 & $0.56-1.19$ & 0.27 \\
\hline
\end{tabular}

ECOG PS: Eastern Cooperative Oncology Group performance status; AC: adenocarcinoma; CV: cisplatin + vinorelbine; CRT: concurrent chemoradiotherapy; RT: radiotherapy; OD: once-daily; AH: accelerated hyperfractionation.

clones, which commences about 28 days after RT initiation (18). Therefore, an AH-RT regimen with 4-week RT treatment time may be more efficient than the standard 6-week regimen. The biologically effective dose for early-responding tissue, widely accepted for comparison of different RT regimens (18), was $74.9 \mathrm{~Gy}$ in this study (64 Gy/40 fractions/28 days), 66.2 Gy for the standard dose (60 Gy/30 fractions/30 days), and 79.3 Gy for the high dose used in the RTOG-0617 study (74 Gy/37 fractions/51 days). Considering the high dose (74 Gy) failed to improve local control and OS, LRC improvement in the current AH-RT regimen was possibly due to both shortened RT treatment time and moderate dose escalation. Although a recent study showed that better local control of advanced NSCLC can lead to improved OS (19), an OS advantage for the AH-RT group was not seen in the current study. We believe this was due to potential deviation in administration of salvage therapy, including EGFR tyrosine-kinase inhibitors or immunotherapy, which was not considered in this PSM, and 
Wada et al: Radiation for stage III NSCLC

Table IV. Summary of sensitivity analysis comparing accelerated hyperfractionated radiotherapy (AH-RT) with once daily radiotherapy (OD-RT): Cox regression models for overall survival, progression free survival, and locoregional control rate.

\begin{tabular}{lccccccccc}
\hline & \multicolumn{3}{c}{ Overall survival } & \multicolumn{3}{c}{ Progression-free survival } & \multicolumn{3}{c}{ Locoregional control rate } \\
\cline { 2 - 9 } AH- $v$ s. OD-RT & HR & $95 \%$ CI & $p$-Value & HR & $95 \%$ CI & $p$-Value & HR & $95 \%$ CI & $p$-Value \\
\hline Unadjusted Cox model & 0.73 & $0.55-0.97$ & 0.03 & 0.63 & $0.48-0.83$ & $<0.01$ & 0.52 & $0.38-0.72$ & $<0.01$ \\
PSM cohort* & 0.75 & $0.46-1.24$ & 0.26 & 0.65 & $0.41-1.03$ & 0.06 & 0.59 & $0.33-0.99$ & 0.04 \\
PSM excluding sex* & 0.71 & $0.43-1.2$ & 0.2 & 0.63 & $0.4-1.02$ & 0.06 & 0.56 & $0.32-0.96$ & 0.03 \\
PSM excluding treatment period* & 0.84 & $0.51-1.41$ & 0.52 & 0.67 & $0.42-1.08$ & 0.09 & 0.50 & $0.51-0.88$ & 0.01 \\
PSM excluding histology* & 0.72 & $0.42-1.23$ & 0.22 & 0.67 & $0.41-1.08$ & 0.09 & 0.52 & $0.29-0.92$ & 0.02 \\
Cox model adjusted for variables & 0.98 & $0.71-1.38$ & 0.92 & 0.75 & $0.56-1.02$ & 0.06 & 0.63 & $0.44-0.9$ & 0.01 \\
with $p<0.2$ in univariate analysis & & & & & & & & & \\
IPTW & 0.99 & $0.7-1.41$ & 0.97 & 0.74 & $0.53-1.03$ & 0.08 & 0.69 & $0.46-1.05$ & 0.07 \\
Cox model adjusted for PS & 1.01 & $0.72-1.43$ & 0.93 & 0.76 & $0.56-1.04$ & 0.08 & 0.63 & $0.43-0.91$ & 0.01 \\
\hline
\end{tabular}

HR: Hazard ratio; 95\% CI: 95\% confidence interval; PS: Eastern Cooperative Oncology Group performance status; PSM: propensity score matching; IPTW: inverse probability of treatment weighting. *Adjusted for matched design in the PSM cohorts.

the relatively large number of deaths from other causes in the AH-RT group. One other variable in the multivariate analysis, treatment period, may also be a surrogate for difference in staging, including the 6th and 7th UICC editions, and the improvement of the modality used for staging, especially the use of positron-emission tomography/CT, which can positively affect clinical outcomes (20). The $\mathrm{N}$ classification (0-2 vs. 3) and number of chemotherapy cycles were strong predictors of metastatic disease, as reported in previous studies $(2,21)$. Sex may be a surrogate for genetic background, including EGFR mutations or Ifestyle and environmental factors, as previously reported (22). RT delay was associated with poorer OS in multivariate analysis. We consider that RT delay may be a surrogate for the presence of complications or poor general patient condition because it did not worsen LRC and PFS.

Critical treatment-related AEs were observed in some patients. Out of nine deaths due to treatment-related AEs, eight were due to lung events, while deaths from cardiac events were observed in two. RTOG-0617 hypothesized that higher heart dose in the high-dose group (74 Gy) might be responsible for the poor clinical result. However, they had no data on the true cause of death (7). In this study, cause of death was confirmed, showing that few of patients died of cardiac events compared with lung events in this cohort $(2 \mathrm{vs}$. 8 patients). The relationship between cardiac events and CRT was not detected. Although the result might change when OS improves by immunotherapy combined with conventional CRT, which has demonstrated promising clinical benefit in advanced lung cancer (23), our findings showed that dose constraint to the lung should have more priority than that to the heart in current CRT without immunotherapy.

A Iimitation of our study includes its retrospective design, which might have introduced selection bias into the dataset. Despite the PSM approach, the possibility of unaccounted bias persisted. Because of the long observation period, staging modalities, clinical care for AEs, and salvage therapy, were altered. In addition, EGFR data were lacking for half of the patients. Therefore, salvage treatment after recurrence including EGFR (TKI) might explain some, or all, of the observed difference. The strength of our study includes the relative homogeneity of the RT regimen. Data on cause of death were obtained for most patients.

In conclusion, our PSM analysis of patients with locally advanced NSCLC undergoing CCRT with AH-RT compared with conventional OD-RT revealed improved LRC and PFS in the AH-RT group, but no superiority in OS. The number of deaths due to cardiac events was small; therefore, reducing the RT dose to the lung should be prioritized over that to the heart. Regarding the fact that shortened RT treatment time and moderate dose escalation may be needed for advanced NSCLC, the AH-RT regimen can be a promising option instead of moderate dose escalation using OD-RT. Additional studies may be required to confirm the present results.

\section{Funding}

This study did not receive funding from any external source.

\section{Conflicts of interest}

The Authors declare no conflict of interest in regard to this study.

\section{References}

1 Perez CA, Stanley K, Rubin P, Kramer S, Brady L, PerezTamayo R, Brown GS, Concannon J, Rotman M and Seydel HG: A prospective randomized study of various irradiation doses and fractionation schedules in the treatment of inoperable non-oatcell carcinoma of the lung. Preliminary report by the Radiation Therapy Oncology Group. Cancer 45: 2744-2753, 1980. 
2 Curran WJ, Paulus R, Langer CJ, Komaki R, Lee JS, Hauser S, Movsas B, Wasserman T, Rosenthal SA, Gore E, Machtay M, Sause W and Cox JD: Sequential vs. concurrent chemoradiation for stage III non-small cell lung cancer: Randomized phase III trial RTOG 9410. J. Natl. Cancer Inst 103: 1452-1460, 2011.

3 Bradley JD, Moughan J, Graham MV, Byhardt R, Govindan R, Fowler J, Purdy JA, Michalski JM, Gore E and Choy H: A phase I/II radiation dose escalation study with concurrent chemotherapy for patients with inoperable stages I to III nonsmall-cell lung cancer: Phase I results of RTOG 0117. Int J Radiat Oncol Biol Phys 77: 367-372, 2010.

4 Socinski MA, Blackstock AW, Bogart JA, Wang X, Munley M, Rosenman J, Gu L, Masters GA, Ungaro P, Sleeper A, Green M, Miller AA and Vokes EE: Randomized phase II trial of induction chemotherapy followed by concurrent chemotherapy and doseescalated thoracic conformal radiotherapy (74 Gy) in stage III non-small-cell lung cancer: CALGB 30105. J Clin Oncol 26: 2457-2463, 2008.

5 Stinchcombe TE, Lee CB, Moore DT, Rivera MP, Halle J, Limentani S, Rosenman JG and Socinski MA: Long-term followup of a phase I/II trial of dose escalating three-dimensional conformal thoracic radiation therapy with induction and concurrent carboplatin and paclitaxel in unresectable stage IIIA/B non-small cell lung cancer. J Thorac Oncol 3: 1279-1285, 2008.

6 Schild SE, McGinnis WL, Graham D, Hillman S, Fitch TR, Northfelt D, Garces YI, Shahidi H, Tschetter LK, Schaefer PL, Adjei A and Jett J: Results of a phase I trial of concurrent chemotherapy and escalating doses of radiation for unresectable non-small-cell lung cancer. Int J Radiat Oncol Biol Phys 65: 1106-1111, 2006.

7 Bradley JD, Paulus R, Komaki R, Masters G, Blumenschein G, Schild S, Bogart J, Hu C, Forster K, Magliocco A, Kavadi V, Garces YI, Narayan S, Iyengar P, Robinson C, Wynn RB, Koprowski C, Meng J, Beitler J, Gaur R and Curran W Jr., Choy $\mathrm{H}$ : Standard-dose versus high-dose conformal radiotherapy with concurrent and consolidation carboplatin plus paclitaxel with or without cetuximab for patients with stage IIIA or IIIB non-smallcell lung cancer (RTOG 0617): A randomised, two-by-two factorial phase 3 study. Lancet Oncol 16: 187-199, 2015.

8 Fu XL, Jiang GL, Wang LJ, Qian H, Fu S, Yie M, Kong FM, Zhao S, He SQ and Liu TF: Hyperfractionated accelerated radiation therapy for non-small cell lung cancer: clinical phase I/II trial. Int J Radiat Oncol Biol Phys 39: 545-552, 1997.

9 Saunders M, Dische S, Barrett A, Harvey A, Griffiths G and Palmar M: Continuous, hyperfractionated, accelerated radiotherapy (CHART) versus conventional radiotherapy in non-small cell lung cancer: Mature data from the randomised multicentre trial. CHART Steering Committee. Radiother Oncol 52: 137-148, 1999.

10 Mauguen A, Le Péchoux C, Saunders MI, Schild SE, Turrisi AT, Baumann M, Sause WT, Ball D, Belani CP, Bonner JA, Zajusz A, Dahlberg SE, Nankivell M, Mandrekar SJ, Paulus R, Behrendt K, Koch R, Bishop JF, Dische S, Arriagada R, De Ruysscher D and Pignon JP: Hyperfractionated or accelerated radiotherapy in lung cancer: An individual patient data metaanalysis. J Clin Oncol 30: 2788-2797, 2012.

11 Imamura F, Konishi K, Uchida J, Nishino K, Okuyama T, Kumagai T, Kawaguchi Y and Nishiyama K: Novel chemoradiotherapy with concomitant boost thoracic radiation and concurrent cisplatin and vinorelbine for stage IIIA and IIIB nonsmall-cell lung cancer. Clin Lung Cancer 15: 281-286, 2014.
12 Sobin $\mathrm{LH}$ and Wittekind $\mathrm{CH}$ (eds.): Union for International Cancer Control. TNM Classification of Malignant Tumors, Sixth Edition. Oxford, UK: John Wiley, 2002.

13 Sobin LH, Gospodarowicz MK and Wittekind CH (eds): Union for International Cancer Control. TNM Classification of Malignant Tumors, Seventh edition. Oxford, UK: John Wiley, 2009.

14 Baggins B: Prescribing, Recording and Reporting Photon Beam Therapy. Report 62; Supplement to Report 50. Bethesda: International Commission Radiation Units and Measurements, 1999.

15 Austin PC: An introduction to propensity score methods for reducing the effects of confounding in observational studies. Multivariate Behav Res 46: 399-424, 2011.

16 Baumann M, Herrmann T, Koch R, Matthiessen W, Appold S, Wahlers B, Kepka L, Marschke G, Feltl D, Fietkau R, Budach V, Dunst J, Dziadziuszko R, Krause M and Zips D: Final results of the randomized phase III CHARTWEL-trial (ARO 97-1) comparing hyperfractionated-accelerated versus conventionally fractionated radiotherapy in non-small cell lung cancer (NSCLC). Radiother Oncol 100: 76-85, 2011.

17 McMillan MT, Ojerholm E, Verma V, Higgins KA, Singhal S, Predina JD, Berman AT, Grover S, Robinson CG and Simone CB 2nd: Radiation treatment time and overall survival in locally advanced non-small cell lung cancer. Int J Radiat Oncol 98: 1142-1152, 2017.

18 Hall EJ and Giaccia AJ: Radiobiology for the Radiologist. Seventh Edition. Philadelphia, PA, USA; Lippincott Williams Wilkins, 2011.

19 Aupérin A, Le Péchoux C, Rolland E, Curran WJ, Furuse K, Fournel P, Belderbos J, Clamon G, Ulutin HC, Paulus R, Yamanaka T, Bozonnat MC, Uitterhoeve A, Wang X, Stewart L, Arriagada R, Burdett S and Pignon JP: Meta-analysis of concomitant versus sequential radiochemotherapy in locally advanced non-small-cell lung cancer. J Clin Oncol 28: 2181-2190, 2010.

20 Eberhardt WE, De Ruysscher D, Weder W, Le Péchoux C, De Leyn P, Hoffmann H, Westeel V, Stahel R, Felip E and Peters S: Second ESMO Consensus Conference in Lung Cancer: locally advanced stage III non-small-cell lung cancer. Ann Oncol 26: 1573-1588, 2015.

21 Berghmans T, Paesmans M and Sculier J-P: Prognostic factors in stage III non-small cell lung cancer: a review of conventional, metabolic and new biological variables. Ther Adv Med Oncol 3: 127-138, 2011.

22 Hsieh RK, Lim KH, Kuo HT, Tzen CY and Huang MJ: Female sex and bronchioloalveolar pathologic subtype predict EGFR mutations in non-small cell lung cancer. Chest 128: 317-321, 2005.

23 Antonia SJ, Villegas A, Daniel D, Vicente D, Murakami S, Hui R, Yokoi T, Chiappori A, Lee KH, de Wit M, Cho BC, Bourhaba M, Quantin X, Tokito T, Mekhail T, Planchard D, Kim YC, Karapetis CS, Hiret S, Ostoros G, Kubota K, Gray JE, Paz-Ares L, de Castro Carpeño J, Wadsworth C, Melillo G, Jiang H, Huang Y, Dennis PA and Özgüroğlu M: Durvalumab after chemoradiotherapy in stage III non-small cell lung cancer. $\mathrm{N}$ Engl J Med 377: 1919-1929, 2017.

Received August 27, 2018

Revised September 16, 2018

Accepted September 21, 2018 